\title{
Os usos da água no espaço rural da microbacia do rio São Mateus, Biguaçú/SC
}

\section{Water uses in the rural area of the são mateus river micro watershed, in Biguaçú/SC}

\author{
Janete $\mathrm{Facco}^{1 *}$, Janete webler Cancelier ${ }^{2}$, Helena Maria Beling ${ }^{3}$, Lisane Regina Vidal \\ Conceição ${ }^{4}$
}

\begin{abstract}
RESUMO
O Bioma Mata Atlântica vem sofrendo grandes transformações ao longo do tempo, suas áreas sendo convertidas em espaços para produção agrícola, cidades e áreas industriais. A ocupação humana tem gerado aceleração na degradação dos ambientes naturais, que também ocorre no meio rural para fins agrícolas. O objetivo é analisar a relação que as pessoas residentes na área da microbacia do rio São Mateus, Biguaçú/SC, possuem com a água, e a importância deste recurso para as propriedades rurais. A opção pela área de pesquisa decorre da indagação em compreender se o modelo de ocupação presente interfere na qualidade da água nessa microbacia. A metodologia foi baseada na abordagem qualitativa. Para seu desenvolvimento, utilizou-se a pesquisa teórica, documental e de campo, além da aplicação de questionários. Como resultado, observa-se que os principais problemas ambientais presentes estão relacionados a crescente poluição das águas superficiais por agrotóxicos, a inexistência de mata ciliar ao longo da microbacia e cursos d'água assoreados.
\end{abstract}

Palavras-chave: Agricultura familiar; Propriedades rurais; Recursos hídricos.

\begin{abstract}
The Atlantic Forest Biome has been suffering major transformations over time, being converted into spaces for agricultural production, cities and industrial areas. Human occupation has generated acceleration in natural environment degradation, which also occurs in coastal areas in countryside for agricultural purposes. The purpose is to analyze the relationship between people who live in the area of São Mateus River micro watershed, Biguaçú/SC, and the water, in addition to the importance of this resource for rural properties. Our choice for the research area came from a inquire of understanding whether the present occupation model interferes with water quality in this particular micro watershed. Our methodology was based on a qualitative approach. For its development we used bibliographic, documentary and field researches, in addition to application of questionnaires. Results show that the main environment problems are related to the increasing pollution of surface water by pesticides, the lack of riparian forest along the micro watershed and silted water courses.
\end{abstract}

Keywords: Family farming; Rural properties; Water resources.

\footnotetext{
${ }^{1}$ Professora da rede estadual de ensino de SC.

*E-mail: janetefacco1@gmail.com

${ }^{2}$ Professora Formadora UAB/CAPES da UFSM. E-mail: janetewc@ gmail.com

${ }^{3}$ Universidade Federal de Santa Maria. E-mail: helenabeling2015@gmail.com

${ }^{4}$ Professora da rede estadual e municipal de ensino do municipio do RS. E-mail: lisanevidal@gmail.com
} 


\section{INTRODUÇÃO}

A ocupação humana crescente e, na maioria das vezes, sem planejamento, tem gerado uma acelerada degradação dos ambientes naturais. Alterações de canais de drenagem por obras de retificação, a extração irregular de recursos minerais, o desmatamento, os aterros inadequados em manguezais e o manejo incongruente da terra para fins agrícolas em declividades acentuadas são exemplos da interferência humana. A maior parte destas ações resultam da falta de conhecimentos básicos dos múltiplos processos naturais que nela ocorrem (SILVA, 2007).

Ao longo da história, nos mais distintos espaços, a ocupação humana se estabeleceu gradualmente em lugares com disponibilidade de água, recurso essencial para o desenvolvimento e sobrevivência. O processo de sedentarização se amplia na medida em que os homens passam a utilizar de forma mais abrangente a água dos rios para atender as necessidades básicas, como o cultivo de alimentos. Assim, a agricultura, em suas mais diversas formas e configurações que conhecemos na atualidade, é o resultado de um longo e complexo processo histórico iniciado há mais de 10.000 anos (BAUER, 2012) e esse desenvolvimento está diretamente relacionado à disponibilidade e utilização de água.

A problemática observada na área deste estudo é um reflexo dos usos do solo e da influência da disponibilidade hídrica no decorrer das décadas e como consequências, falta de mata ciliar, falta de cuidados no manuseio de agrotóxicos e a diminuição na quantidade de água disponível para o desenvolvimento de atividades nas propriedades. Neste contexto, este trabalho objetiva compreender a relação existente entre as práticas agrícolas adotadas pelos agricultores e a importância da água para o desenvolvimento das atividades na área da microbacia São Mateus, localizada no município de Biguaçú/SC.

Especificamente, busca-se: observar como ocorre o uso do solo e as práticas agrícolas adotadas; verificar a existência da mata ciliar nas margens dos rios; analisar a relação entre as atividades realizadas e o uso da água; verificar como os agricultores acessam a água; verificar quais são os agrotóxicos utilizados; e, identificar quais são os impactos ambientais ocasionados pelas atividades agrícolas realizadas.

A justificativa ocorre com vistas a revelar a importância deste recurso para a manutenção da vida e o desenvolvimento das atividades agrícolas nas propriedades 
rurais, assegurando a permanência do homem no campo. A opção pela área decorre da indagação do problema em compreender se o modelo de ocupação adotado interfere na qualidade da água dessa microbacia?

\section{MATERIAIS E MÉTODOS}

A pesquisa caracteriza-se pela abordagem qualitativa e apresenta uma análise descritiva e interpretativa. Para seu desenvolvimento, utilizou-se a pesquisa teórica, documental e de campo.

Os dados qualitativos foram obtidos, no ano de 2019, por meio de entrevistas semi estruturadas dirigidas a 14 sujeitos residentes na Microbacia do Rio São Mateus, município de Biguaçu/SC e ao técnico da Empresa de Pesquisa Agropecuária e Extensão Rural de Santa Catarina (EPAGRI), que trabalha diretamente com os agricultores da Microbacia. A amostragem se caracteriza por ser de cunho não probabilística e selecionada pelo critério da acessibilidade, englobou, essencialmente, agricultores familiares pertencentes à Associação de Agricultores da Microbacia, denominados de A1 a A14. Aos pesquisados, apresentou-se os objetivos do trabalho, orientou-se sobre o sigilo e anonimato dos dados, bem como informou-se a todos a respeito do Termo de Confidencialidade, o qual foi lido e assinado voluntariamente pelos pesquisados. As entrevistas ocorreram via aplicação de questionário, o qual continha questões abertas e fechadas, e seguiram um roteiro determinado de questões, as quais procuravam conhecer a forma de utilização da água, a relação e a importância da água para os agricultores dessa Microbacia, bem como o histórico do uso da terra.

Para dar visibilidade aos fenômenos pesquisados, utilizou-se a técnica do registro fotográfico, a qual foi realizada durante o trabalho de campo, nos espaços autorizados. As reflexões acerca do objeto de pesquisa também foram desenvolvidas com uso do diário de campo. Os procedimentos e técnicas utilizadas permitiram o acesso às informações e compreender com maior nível de detalhamento a realidade vivenciada pelos agricultores.

\section{ÁREA DE ESTUDO}

O município de Biguaçu/SC (Figura 1), faz parte da região metropolitana da Grande Florianópolis. Possui área territorial de 367,870 $\mathrm{Km}^{2}$ e, no ano de 2019, a população total estimada era de 68.481 habitantes, com uma densidade demográfica de 
156,94 hab/km² (IBGE, 2019). 90,6\% da população residiam na área urbana e 9,4\% na área rural. As dificuldades de reprodução socioeconômica no campo, associadas a proximidade com a capital estadual e com o município de Palhoça, área urbana com maior infraestrutura e oportunidades, principalmente no setor terciário, tem atraído os jovens de forma contínua ao longo dos anos, ampliando o êxodo rural. Este é um processo que, em diferentes intensidades, se manifesta praticamente em todos os estados brasileiros.

Figura 1- Localização da área de pesquisa.

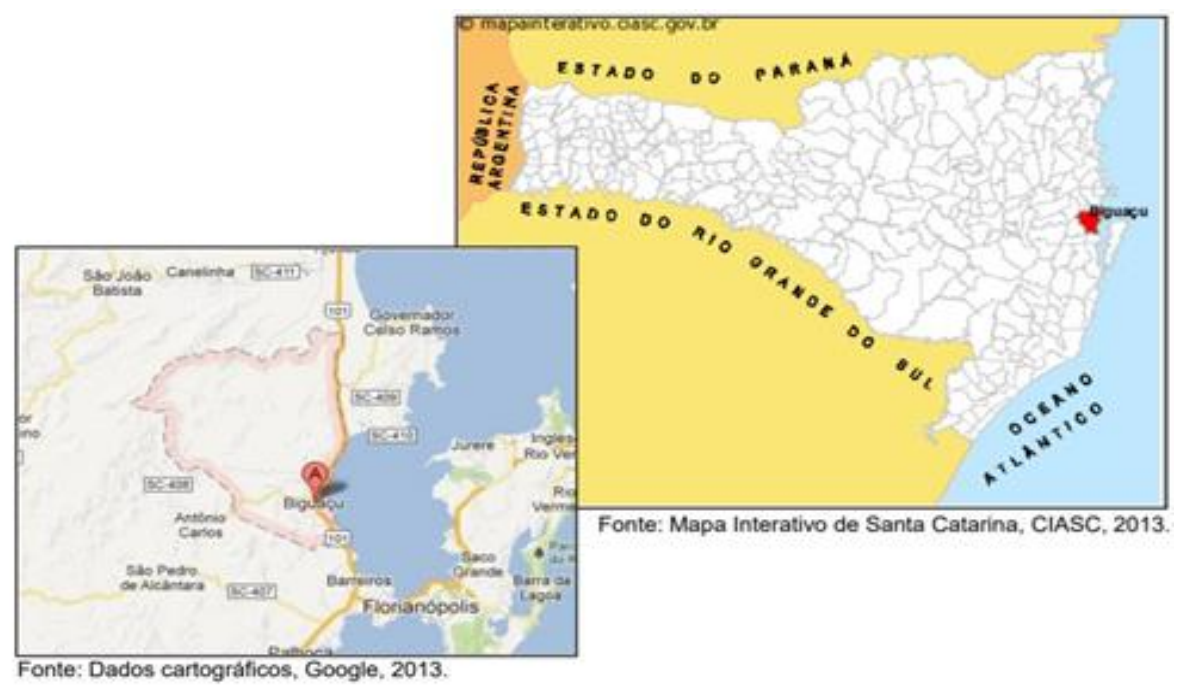

Fonte: adaptado pelas autoras (2020).

A área rural do município possui 346 estabelecimentos agropecuários, totalizando uma área de 7.801 hectares (ha). Desse total, 280 agricultores são proprietários, os demais arrendatários. Do total de estabelecimentos, 127 faziam uso de agrotóxicos no ano de 2017 (IBGE, 2017), dado que representa um total de 37\% dos estabelecimentos agropecuários. Em relação à utilização da terra, 3.431 ha são ocupados por pastagens, das quais 3.181ha com pastagens naturais e 250 ha plantadas. As lavouras permanentes e temporárias ocupam 1.195 ha, e matas e florestas 2.941 ha. Nas lavouras permanentes estão presentes os cultivos de banana, goiaba e maracujá, nas lavouras temporárias arroz, cana de açúcar, aipim, milho (IBGE, 2017).

Inserido neste cenário está a Microbacia do rio São Mateus, objeto deste estudo, que possui uma área territorial de $38,4 \mathrm{~km}^{2}$, espaço onde vivem 287 famílias de agricultores familiares (VICENTE; FANTINI, 2014). Sob o ponto de vista do relevo, as áreas planas compõem $6,19 \mathrm{~km}^{2}$, com altitude de 20 metros e, a maior parte é formada 
por terrenos de morro $\left(32,23 \mathrm{~km}^{2}\right)$ com elevações de até $586 \mathrm{~m}$ de altitude e declividades predominantemente acima de 30\% (SILVA, 2007).

No que tange à paisagem predominam áreas de relevo acidentado, espaços nos quais estão alicerçadas práticas agrícolas desenvolvidas por agricultores familiares. As atividades desenvolvidas ocorrem principalmente a partir dos conhecimentos repassados de geração a geração. $\mathrm{O}$ uso de práticas agrícolas inadequadas realizadas ao longo dos anos, nesta área tem ocasionado uma crescente estagnação produtiva, ampliado os impactos ambientais e, consequentemente, comprometendo a reprodução e permanência no campo.

\section{O PERFIL DA POPULAÇÃO E A IMPORTÂNCIA DA ÁGUA}

Conforme Vicente; Fantini (2014), as atividades de manejo praticadas pela população local nas encostas declivosas das microbacias se fundamentam na supressão florestal para obtenção de lenha e uso do solo fertilizado, que é fruto tanto do pousio como das cinzas resultantes da queima da biomassa. A pressão sobre as áreas florestais do bioma Mata Atlântica levou a necessidade de se regulamentar a utilização de seus recursos (BAUER, 2012).

Um marco no controle do uso dos recursos florestais no país foi à promulgação da Lei 4.771/65, conhecida como Código Florestal Brasileiro (BRASIL, 1965), o qual, restringiu a utilização de florestas primárias e estabeleceu a necessidade de reservar áreas para preservação em todos os estabelecimentos agrícolas, nas categorias Área de Reserva Legal e Áreas de Preservação Permanente (BAUER, 2012).

Por sua vez, na Constituição Federal de 1988 está destacada a função social da propriedade, sendo evidenciados os direitos e deveres dos detentores da propriedade privada. Nessa ordem, o artigo 186 dispõe sobre a constitucionalização da função social da propriedade rural e seus requisitos, sendo que, a função social é cumprida quando a propriedade rural atende, simultaneamente, aos seguintes requisitos: II - utilização adequada dos recursos naturais disponíveis e preservação do meio ambiente; III observância das disposições que regulam as relações de trabalho; IV - exploração que favoreça o bem-estar dos proprietários e dos trabalhadores (BRASIL, 1988, s/p). Assim, a Constituição traz a obrigatoriedade de cuidar do meio ambiente e dos recursos naturais. 
No que se refere aos instrumentos legais específicos para a Mata Atlântica, foi regulamentada, em 1993, através do Decreto Federal n 750 , os limites para o uso e conservação da Mata Atlântica, proibindo a exploração e a supressão da vegetação primária e nos estágios de regeneração médio e avançado. Na região da pesquisa, "a formação florestal predominante é a Floresta Ombrófila Densa (FOD), a qual se estende pela região litorânea do estado e é uma das regiões fitoecológicas do bioma Mata Atlântica" (VICENTE; FANTINI, 2014, p. 185).

Em 2006 foi aprovada a Lei 11.428 (Lei da Mata Atlântica), que passou a disciplinar as possibilidades de uso dos recursos florestais da mesma, porém, as florestas passaram a ser vistas pelos agricultores como um empecilho ao atendimento de suas necessidades (BAUER, 2012). Em decorrência, os agricultores seguem naturalmente realizando as práticas agrícolas, sem uma efetiva preocupação com o previsto na Lei. A preocupação ocorre quando recebem uma visita de fiscais, os quais se deslocam as propriedades para verificar denúncias de crime ambiental.

A partir do trabalho de campo, constatou-se que, na Microbacia do rio São Mateus, a dificuldade que os agricultores familiares têm em adquirir novas terras devido à inexistência de áreas e de capital para aquisição, aliado a declividade das unidades de relevo presentes, ocasionam na exploração desenfreada dos recursos naturais. Ao longo dos anos, esse processo tem gerado perda da fertilidade natural dos solos e a contaminação dos recursos hídricos, ocasionando queda na produtividade e na rentabilidade da agricultura.

A maioria da população que vive na área rural está inserida na faixa etária de 35 a 75 anos. Em relação a escolaridade dos agricultores pesquisados, verificou-se que $70 \%$ estudaram até o $4^{\circ}$ ano do Ensino Fundamental e que, 30\% são analfabetos. O abandono do campo pelos jovens é um fenômeno presente, que acaba por contribuir na intensificação do envelhecimento da população rural, na ausência de sucessores familiares, bem como na própria continuidade das atividades agropecuárias. Este resultado já denota a necessidade de pensar alternativas, tornando as atividades do campo mais atrativas à presença e viáveis a permanência dos jovens.

Desta forma, acredita-se que a valorização e políticas de incentivo a permanência do homem no campo devem ser vistas como políticas de Estado, pois, se observa, não apenas na área estudada, mas no meio rural brasileiro, essa desvalorização do campo em detrimento da cidade e, cada vez mais, os dados estatísticos coletados e 
mensurados denotam tal dinâmica, o que compromete até mesmo a suficiência alimentar do país, pois, significativa parte dos alimentos que atendem as demandas alimentares da população são oriundos da agricultura familiar.

Outro elemento observado, que chama a atenção, se refere ao fato de todos os pesquisados apresentarem o mesmo histórico familiar: são filhos e netos de agricultores que nasceram na região, compondo assim a terceira geração de habitantes da localidade. Dessa maneira, Vicente; Fantini (2014, p. 189), enfatizam que "[...] as famílias locais apresentam relação direta com a floresta sendo o elemento-chave do modo de vida destes agricultores silvicultores". Os agricultores justificam a retirada das áreas com floresta mais antiga, ou até mesmo de parte delas, em função da necessidade de ampliar a área de cultivo, bem como a necessidade de lenha para o abastecimento familiar.

De acordo com a pesquisa, as principais atividades desenvolvidas nas propriedades são: cultivo de arroz, mandioca, feijão, milho, verduras, legumes, bananas, cana, leite, carvão de toco e eucalipto. Em relação à renda, os depoentes não informaram valores, o que pode decorrer das implicações contábeis e jurídicas em disponibilizar dados dessa natureza, contudo, enfatizaram que as atividades mais rentáveis estão vinculadas ao cultivo de arroz, mandioca, bananas, verduras e legumes. Estes produtos são comercializados diretamente com mercados da região e a Central de Abastecimento Sociedade Anônima (CEASA) da grande Florianópolis, de maneira in natura (A-1, 2019). A proximidade dos mercados e a facilidade de acesso possibilitam que os próprios agricultores levem seus produtos ao mercado, eliminando os intermediários, viabilizando maior entrada de renda na unidade de produção familiar.

A permanência de todas as atividades praticadas está diretamente vinculada à disponibilidade de água, sendo que "[...] o cultivo do arroz corresponde a uma das atividades que mais consome água no seu processo produtivo, seguido pelas verduras e legumes" (A-12, 2019). A inserção de cultivos diversificados e da pecuária tem possibilitado novas dinâmicas sociais e econômicas aos agricultores. Procurando viabilizar as unidades, estes investem em várias atividades e, posteriormente, mantêm o foco nas que oferecem maior retorno. Assim, percebe-se uma diversificação na produção, mas ao mesmo tempo, uma especialização de determinadas atividades mais rentáveis e de fácil comercialização. Tal prática contribui para um maior rendimento financeiro dos agricultores, bem como formas de assegurar várias fontes de renda, à 
medida que mantém uma produção diversificada e também produtos com maior rentabilidade.

Neste sentido, a preservação dos cursos d'água, suas nascentes e matas ciliares são fundamentais para a manutenção do sistema e disponibilidade de água. A partir da figura 2, é possível visualizar uma lavoura de arroz em uma das propriedades que estão inseridas na Microbacia do rio São Mateus.

Figura 2 - Lavoura de arroz em várzea na microbacia São Mateus

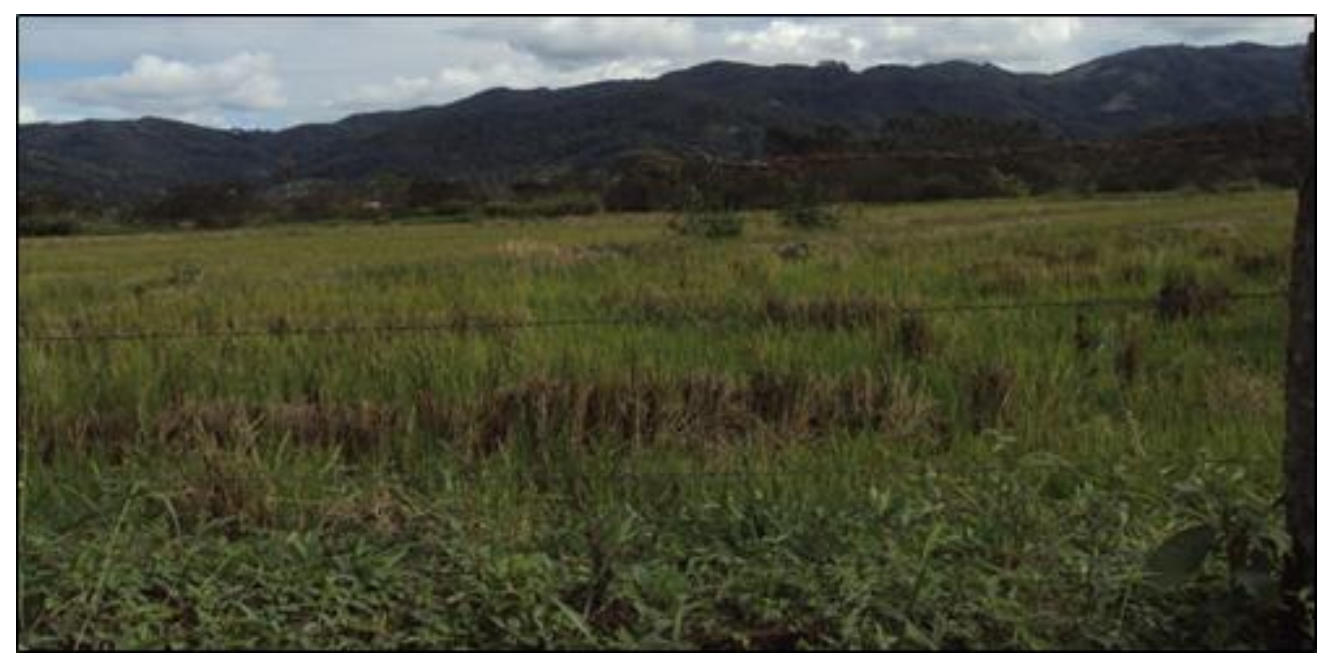

Fonte: autoras (2019).

Todos os trabalhos são realizados predominantemente pela mão de obra familiar. Em determinadas circunstâncias, ocorre a prática denominada "troca de dia de trabalho", que são realizadas entre parentes e vizinhos para as atividades de roçadas, corte de lenha, construção de cercas e ranchos, aplicação de agrotóxicos, plantio e colheita. Portanto, observa-se que a agricultura familiar fixa o homem no campo, à medida que é detentora da utilização da mão de obra dos próprios integrantes do grupo familiar, mas também que suas práticas de ajuda coletiva contribuem para a diminuição do custo de produção e fortalecimento do grupo familiar.

IMPACTOS DAS ATIVIDADES HUMANAS NA DISPONIBILIDADE DE ÁGUA NA MICROBACIA DO RIO SÃO MATEUS

As atividades humanas, ao longo dos anos, vêm impactando de diferentes formas a qualidade da água da Microbacia do rio São Mateus. Os problemas são recorrentes de 
uma série de fatores, entre os quais está a falta de sistemas de tratamento do esgoto doméstico nas propriedades e manejos inadequados nas práticas agrícolas desenvolvidas.

No que se refere às formas de tratamento do esgoto sanitário, $93 \%$ dos entrevistados relatam que possuem em suas propriedades as fossas rudimentares, chamadas de águas negras. O restante, $7 \%$ dos entrevistados, possuem o esgoto a céu aberto. A partir das entrevistas, ainda foi possível observar a inexistência de tratamento adequado aos efluentes proveniente dos chuveiros, lavatórios, tanques e máquinas de lavar roupa. $100 \%$ dos entrevistados alegam que não realizam a destinação correta e que os efluentes escoam a céu aberto em valas que desembocam nos riachos.

A partir das observações realizadas na pesquisa de campo é possível afirmar que não existe uma preocupação para a destinação correta destes efluentes. Os agricultores têm a convicção de que estes não poluem os recursos hídricos, pois "[...] é uma água que só contém sabão e gordura" (A-6, 2019). Historicamente utilizam esta prática, como pode ser observado na fala do entrevistado A-9 (2019), "[...] sempre fizemos assim e nunca tiveram problemas, é uma prática histórica, meus avós e pais já faziam assim". Assim, ainda é muito presente na sociedade a ideia de que a água é um recurso infinito e abundante.

De forma geral, os agricultores que possuem disponibilidade de água para suas atividades não realizam o reaproveitamento. A prática da irrigação via reutilização da água aos olhos dos agricultores é inviável, haja vista que alegam ser necessário um sistema de coleta e distribuição, "[...] o que exige tanques e ou reservatórios, gastos com energia, investimentos, economicamente é inviável, pois temos disponibilidade de água, ainda não existe a necessidade de guardar a água para regar os cultivos (A-9, 2019).

Quando questionados sobre a separação do lixo produzido nas propriedades, $71 \%$ dos entrevistados responderam que fazem a separação entre materiais recicláveis e lixo orgânico. Os resíduos orgânicos são utilizados como alimento para os animais (aves, suínos e gado) e na compostagem. O material reciclável é depositado em um ponto específico da comunidade, onde é recolhido semanalmente pela coleta seletiva. Ainda que todos os entrevistados tenham conhecimento da importância da destinação adequada do lixo, 29\% não fazem a separação dos resíduos, realizando a prática da queima, a qual é proibida por lei. Esta prática ocorre principalmente nas propriedades que se encontram afastadas dos pontos de coleta seletiva, haja vista, que o serviço não 
está disponível para todas as localidades, sendo esta considerada a melhor alternativa para o lixo.

A presença dos resíduos de produtos agrícolas e veterinários enaltecem a problemática em questão. Na Microbacia do rio São Mateus, $86 \%$ dos entrevistados utilizam diversos agrotóxicos. Quando abordados sobre a destinação destas embalagens, todos responderam não realizar descarte de forma correta e que, muitas vezes, acabam queimando as embalagens, jogando-as em determinados lugares na propriedade ou até mesmo, utilizando-as para armazenar outros produtos. Neste caso, justificam tal prática pela falta de coleta dos órgãos responsáveis. Há uma grande preocupação no cenário nacional no que se refere à destinação correta das embalagens de agrotóxicos, isto porque, o Brasil é um dos maiores consumidores mundiais. Segundo, a Lei no 9.974 de 2000, as responsabilidades para destinação pós-consumo das embalagens devem ser divididas entre agricultores, distribuidores, indústria e poder público (BRASIL, 2000).

Em relação à origem da água utilizada, 93\% dos entrevistados utilizam água de nascentes e $7 \%$ de poços superficiais. Observou-se que nessa microbacia existe um grande número de nascentes em quase todas as propriedades, esta disponibilidade, de acordo com o entrevistado A-10 (2019), não torna necessária a prática do reaproveitamento.

No que se refere à presença da mata ciliar, áreas consideradas como Área de Proteção Permanente (APP), segundo o Código Florestal Brasileiro, foi observado que, em $43 \%$ das propriedades a mata está preservada nas laterais dos córregos, em 21\% preservada nas encostas e em $36 \%$ foi toda retirada, como é o caso das áreas destinadas ao pasto, locais onde o gado permanece. A retirada da mata ciliar torna mais suscetível a ampliação dos processos erosivos em períodos de chuvas, determinando a existência de áreas não próprias ao cultivo em função da perda da fertilidade, bem como coloca em risco a própria permanência do rio devido a intensificação do processo de assoreamento. No cenário da área de pesquisa, os agricultores acabaram, ao longo dos anos, utilizando a mata ciliar para suprir as necessidades de lenha.

No espaço geográfico analisado é perceptível problemas relacionados à sustentabilidade dos recursos hídricos, os quais são decorrentes, entre outros, das formas de ocupação do solo. De um lado as estratégias adotadas pelos agricultores frente às restrições impostas ao manejo florestal, cujos agricultores passam a efetuar o desmatamento clandestino como estratégia para manter a superfície agrícola útil e, de 
outro lado, o uso da terra com cobertura permanente do solo, como o manejo de formações florestais nativas, constitui alternativa para promover o bom desempenho ambiental dos proprietários, cuja prática é evidenciada por Bauer (2012).

Os conflitos em relação ao uso do solo são evidenciados nas falas dos entrevistados, ao tecer comentários sobre a qualidade do ambiente, A-8 (2019) expõe “[...] apesar da água ser boa, perde-se muita terra com nascentes e rios", A-14 (2019) ressalta “[...] a água é boa para nós, para os animais e para irrigação de arroz". Paradoxalmente, pode-se afirmar que existe um conflito de interesse no uso do solo em relação ao cenário econômico e ambiental. A área ocupada pela água é vista pelos agricultores como um obstáculo à ampliação da área disponível para a produção, ainda que todos concordem que necessitam dela.

Ao longo dos anos, a paisagem da microbacia vem se transformando. Agricultores acabam suprimindo a mata ciliar e inserindo cultivos de eucaliptos nas áreas adjacentes às nascentes, buscando diminuir a área ocupada pela água, o que inegavelmente prejudica a manutenção do ecossistema. Estas atitudes, causam profundas transformações na paisagem e na disponibilidade de água, sendo evidente a diminuição do volume no decorrer das décadas.

No período em que a pesquisa foi realizada, ano de 2019, alguns agricultores salientaram que já estavam observando alterações nas paisagens, principalmente em relação aos cursos d'água que cortam as propriedades. Como pode ser observado no relato do entrevistado A-2 (2019), ao abordar que: "[...] na época em que era criança nadava onde, hoje, consigo atravessar a pé para tocar o gado de um lado para o outro".

Quando questionados sobre problemas relacionados à diminuição da produção pela falta de água nas propriedades em alguma estação do ano, 57\% dos entrevistados relataram que nunca tiveram. Porém, 43\% evidenciam que, em algum período, já sofreram com a falta de água na propriedade, perdendo parte da produção. Para estes, a alternativa foi buscar água na propriedade do vizinho, inclusive para os animais. Contudo, estes depoentes salientam que este fenômeno não ocorre todos os anos, mas consideram necessário pensar em alternativas para sanar essas dificuldades nos períodos de estiagens. Como sobrevivem da agricultura, necessitam da água para manter seus cultivos, neste grupo estão principalmente os que produzem hortaliças, verduras e frutas. 
É consenso entre todos os agricultores que o excesso de chuvas provoca mais estragos à produção do que a falta da mesma. Devido à localização geográfica da Microbacia São Mateus, fundo de um vale, a chuva é constante e, em períodos mais intensos, ocorrem alagamentos nas áreas de várzea, bem como deslizamentos de encostas.

Outro elemento observado e confirmado pelos agricultores se refere a alguns cursos d'água serem desviados de seu leito natural em função da necessidade da irrigação do cultivo do arroz. Essa prática vem se ampliando na área e além de mudar a dinâmica natural dos rios e córregos acaba contribuindo para a perda da vazão dos cursos d'água e de sua biodiversidade. Ainda está diretamente relacionada à diminuição da disponibilidade de água em algumas propriedades e na contaminação pelos agrotóxicos, impossibilitando o uso para o abastecimento das residências e animais.

Ao serem questionados se tinham conhecimento dos danos que os agrotóxicos causam à saúde e ao meio ambiente, principalmente aqueles especificados nos rótulos das embalagens, $100 \%$ dos entrevistados alegam não ler as informações. A desinformação e a falta de preocupação em buscá-las coloca em risco a saúde do agricultor, da família e do meio ambiente. Na medida em que, alguns agrotóxicos utilizados são considerados extremamente tóxicos e exigem manuseios específicos, $67 \%$ do grupo alegam que possuem dúvidas sobre a aplicação, o processo de lavagem e destinação das embalagens.

Todos os agricultores pesquisados não visualizam, a curto prazo, que exista uma relação entre saúde e contato com agrotóxicos. A busca por melhores resultados na produção os leva a utilizar, frequentemente, agrotóxicos. A justificativa mais utilizada pelos depoentes está relacionada à carência de mão de obra familiar e a quantidade de trabalho a ser realizado na propriedade. A preocupação com a contaminação da água não está presente, ainda que todos dependem diretamente dela para manter seus cultivos.

Ao longo dos anos os agricultores foram substituindo cultivos, bem como as formas de uso do solo, todas estas mudanças impactam de distintas formas a Microbacia do rio São Mateus, na medida em que são constantes as intervenções humanas no espaço geográfico. Os agricultores ainda evidenciam que, nos últimos anos, principalmente a partir de 2010, as mudanças nas políticas ambientais têm limitado o uso da terra e das atividades vinculadas à exploração dos recursos naturais presentes nas 
áreas da microbacia. No entanto, apesar da legislação ser abrangente e atuar no sentido de proteger e orientar a utilização de forma sustentável e racional os recursos presentes, ainda persistem problemas que colocam em risco a própria vida do agricultor e o meio ambiente como um todo, como é o caso dos agrotóxicos utilizados pelos agricultores da Microbacia de São Mateus.

Ressalta-se que a prática da utilização desses é bastante difundida na atividade agrícola brasileira, especialmente a partir do processo de modernização da agricultura, com o intuito da diminuição de perdas e aumento da produtividade, fatos estes que são elucidados com as susceptíveis colheitas e safras recordes. Entretanto, a perda da biodiversidade também é perceptível, acrescidos de problemas de saúde que os agricultores vêm enfrentando no decorrer dos anos. Infelizmente, tais práticas, ao longo do tempo, estão contribuindo para a expulsão do homem no campo, pois a contaminação da água e do solo colocam em risco a (re) produção socioeconômica dos agricultores. $\mathrm{Na}$ área de pesquisa, este fenômeno tem se intensificado, principalmente com o cultivo do arroz convencional. As propriedades agrícolas familiares pesquisadas dependem exclusivamente do trabalho familiar e dos recursos naturais para se reproduzirem.

\section{CONSIDERAÇÕES FINAIS}

Esse trabalho objetivou tecer alguns olhares sobre a realidade dos agricultores na microbacia do rio São Mateus. Entre os principais problemas ambientais encontrados destaca-se a inexistência de mata ciliar aos longos dos cursos d'água, o que resulta na erosão e assoreamento dos rios e córregos, bem como perda da vazão ou até mesmo extinção dos cursos d'água. Observou-se também a poluição das águas por agrotóxicos e lixo, desencadeadas por práticas inadequadas de utilização e destino de produtos químicos, como também da falta de separação, coleta e destino adequado dos resíduos. Tais práticas contribuem para a poluição dos recursos naturais e consequentemente, estão associados a problemas de saúde dos agricultores e suas famílias.

O modelo de ocupação e uso do solo realizado na área vem contribuindo com a contaminação dos recursos hídricos. Neste contexto, é essencial que o poder público, junto à comunidade, articule ações buscando minimizar os efeitos ambientais, entre os quais sugere-se: a) análise da qualidade da água na microbacia do rio São Mateus, especialmente no que se refere à presença de agrotóxicos; b) levantamento, 
acompanhamento e controle de doenças simples e complexas que possam estar relacionadas ao consumo de água junto a Unidade de Saúde que atende as famílias; c) propor cursos sobre uso, cuidados e contaminação por agrotóxicos; d) realizar a coleta seletiva de lixo e ampliar a construção de fossas de esgoto no meio rural; e) incentivar pesquisas sobre outras fontes de renda, como a produção orgânica, com intuito de agregar valor aos produtos; f) fomentar parcerias com instituições públicas de pesquisa e extensão objetivando assistência técnica para as atividades desenvolvidas e suporte para o desenvolvimento de novas atividades pautadas no desenvolvimento sustentável e preservação do meio ambiente.

Muitos espaços rurais vêm perdendo sua vitalidade econômica pela ineficiência dos agentes que mobilizam o território, o que implica também uma fragilização sociocultural daqueles que permanecem no campo. Nesse processo, é vital compreender que o espaço rural não é estático, impõe constantes mudanças, sendo, em alguma medida, um palco das manifestações globais, de tal sorte que precisa ser confrontado com os novos contextos presentes nos arranjos produtivos da atualidade. Nesse sentido, pode-se destacar que o espaço geográfico não é inerente às ações humanas, ele próprio é parte dessas ações, é reflexo e condição das materializações do processo de reprodução da sociedade.

\section{REFERÊNCIAS}

BAUER, Eliane. Mudanças no uso da terra em Biguaçu-SC: agricultores em permanente processo de adaptação. Dissertação (mestrado) - Universidade Federal de Santa Catarina, Centro de Ciências Agrárias, Programa de Pós-Graduação em Agroecossistemas, Florianópolis, 2012.

BRASIL. Lei n 4.771 , de 15 de setembro de 1965. Institui o novo Código Florestal. Disponível em: http://www.planalto.gov.br/ccivil_03/leis/14771.htm. Acesso em: 23 de maio 2021.

Constituicão da República Federativa do Brasil de 1988. Disponível em: http://www.planalto.gov.br/ccivil_03/constituicao/constituicao.htm. Acesso em: $27 \mathrm{de}$ maio 2021.

Lei $\mathbf{n}^{\mathbf{0}}$ 9.974, de 6 de junho de 2000. Altera a Lei $\mathrm{n}^{\mathrm{0}}$ 7.802, de 11 de julho de 1989. Disponível em: http://www.planalto.gov.br/ccivil_03/leis/19974.htm. Acesso em: Acesso em: 02 de ago. 2021.

. Lei $\mathrm{n}^{\circ} 11.428$, de 22 de dezembro de 2006. Dispõe sobre a utilização e proteção da vegetação nativa do Bioma Mata Atlântica, e dá outras providências. 
Disponível em: http://www.planalto.gov.br/ccivil_03/_ato20042006/2006/lei/l11428.htm. Acesso em: 02 de ago. 2021.

Lei $\mathrm{N}^{\circ}$ 12.651, de 25 de maio de 2012. Código Florestal Brasileiro. Dispõe sobre a proteção da vegetação nativa. Disponível em:

http://www.planalto.gov.br/ccivil_03/_Ato20112014/2012/Lei/L12651.htm. Acesso em: 10 abr. 2020.

Decreto No 7.830, de 17 de outubro de 2012. Dispõe sobre o Sistema de Cadastro Ambiental Rural, Disponível em:

http://www.planalto.gov.br/CCIVIL_03/_Ato2011-2014/2012/Decreto/D7830.htm.

Acesso em: 10 abr. 2020.

IBGE, Instituto Brasileiro de Geografia e Estatística. Censo agro 2017. 2017.

Disponível https://censos.ibge.gov.br/agro/2017/. Acesso em: 23 de out. 2019.

IBGE, Instituto Brasileiro de Geografia e Estatística. Cidades: Biguaçu. 2019.

Disponível https://cidades.ibge.gov.br/brasil/sc/biguacu/panorama. Acesso em: 23 out. 2019.

PANCERI, B. et al. Tecnologias sociais de baixo custo em sistemas de tratamento de esgoto doméstico na área rural de Gravatal, SC. Florianópolis: Epagri, 2014, 24p. (Epagri. Boletim Didático, 126).

SILVA, Vicente Rocha. Análise socioambiental da bacia do rio Biguaçu-SC: subsídios ao planejamento e ordenamento territorial. Tese de doutorado. Universidade de São Paulo. Programa de Pós-Graduação em Geografia Física. Departamento da Faculdade de Filosofia, Letras e Ciências Humanas. São Paulo-SP, 2007. Disponível https://www.teses.usp.br/teses/disponiveis/8/8135/tde-03122007110403/publico/TESE_VICENTE_ROCHA_SILVA.pdf. Acesso em: 01 ago. 2019.

SIMINSKI, Alexandre; FANTINI, Alfredo Celso. Roça-de-toco: uso de recursos florestais e dinâmica da paisagem rural no litoral de Santa Catarina. Ciência Rural, Santa Maria. v.37, n.3,. p.690-696, mai-jun, 2007. ISSN 0103-8478. Disponível em: http://www.scielo.br/scielo.php?script=sci_abstract\&pid=S010384782007000300014\&lng=en\&nrm=iso. Acesso em: 15 ago. 2019.

VICENTE, Nicole Rodrigues; FANTINI, Alfredo Celso. Transformações no sistema tradicional de roça itinerante na Mata Atlântica do Litoral sul brasileiro. Revista Intheresis. V. 11, n. 2, jul/dez de 2014. ISBN 1807-1384. UFSC, 2014. Disponível em: https://periodicos.ufsc.br/index.php/interthesis/article/view/1807-1384.2014v11n2p183. Acesso em: 10 ago. 2019.

Recebido em: 03/01/2022

Aprovado em: 25/01/2022

Publicado em: 28/01/2022 